\title{
Successful Mechanical Thrombectomy Using Solumbra Technique In a 35-year-old Man With Achondroplasia : a case report
}

\author{
Jun-Soo Cho' ', Sang-Uk Kim ', Hyun-Jeong Kim², Ji-Ho Yang' ', II-Woo Lee', Hyung-Jin Lee \\ 'Department of Neurosurgery, 'Department of Radiology, Deajeon St. Mary's Hospital, College of Medicine, The Catholic \\ University of Korea, Daejeon, Republic of Korea
}

\begin{abstract}
Background : Achondroplasia is one of the most common types of dwarfism and is inherited as an autosomal dominant disease. The patients with achondroplasia suffer from various complications such as craniofacial, central nervous system, spinal, respiratory and cardiac anomalies.
\end{abstract}

Case Description : We report a case of a 35-year-old man with achondroplasia who visited the emergency room with right hemiplegia and aphasia within 6 hours after onset. An Initial CT angiography showed the total occlusion of a left internal cerebral artery due to the thrombus. We treated the patient with endovascular thrombectomy using "Solumbra technique" with balloon guiding catheter. The procedure was successful and result was completely recanalized with Thrombolysis in Cerebral Infarction (TICl) scale 3 and the weakness also improved from grade II to grade IV.

Conclusion : Acute ischemic stroke patients with achondroplasia could be treated with mechanical thrombectomy.

Keywords Achondroplasia, cerebral infarction, thrombectomy
J Cerebrovasc Endovasc Neurosurg. 2019 March;21(1):33-39

Received : 1 November 2018

Revised : 26 January 2019

Accepted : 6 March 2019

Correspondence to Hyung-Jin Lee Department of Neurosurgery, Daejeon St. Mary's Hospital, College of Medicine, The Catholic University of Korea, 64, Daeheung-ro, Jung-gu, Daejeon, 34943, Republic of Korea.

Tel : $+82-42-220-9525$

Fax : +82-42-222-6601

E-mail : kope95@hanmail.net

ORCID : http://orcid.org/0000-0002-5769-3974

\section{INTRODUCTION}

Achondroplasia is one of the most common types of short limbs dwarfism, affecting about 250,000 people worldwide and the incidence is estimated to be 1 in 10,000 to 30,000 live births per year. ${ }^{1126)}$ This disorder follows an autosomal dominant inheritance in $80 \%$ of the cases $^{25)}$ and is caused by a single point gain of functional mutation in the gene encoding fibroblast growth factor receptor (FGFR) 3. ${ }^{21)}$

The patients suffer from various complications such as several craniofacial, central nervous systems, spinal, respiratory and cardiac anomalies besides disproportionate dwarfism. ${ }^{69)}$ A study reported that overall heart disease mortality rate was more than twice that of the general population and eightfold more neurological related deaths. ${ }^{27}$ ) However, there exists little research on the treatment of cerebral infarction in these patients. This is the first reported case of successful treatment of acute ischemic stroke with achondroplasia using mechanical thrombectomy. 

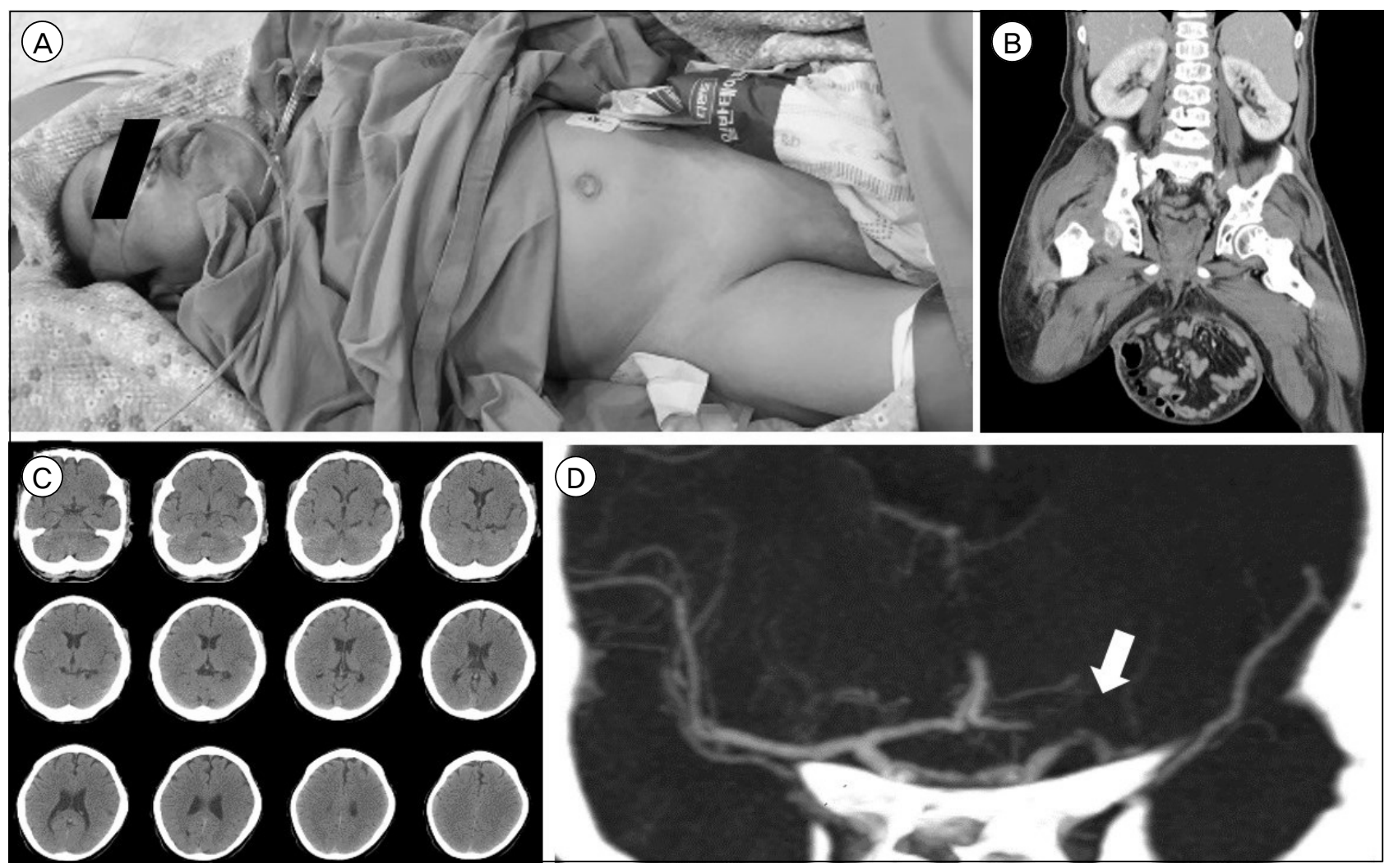

Fig. 1. (A) A 35-year-old man with achondroplasia measuring $130 \mathrm{~cm}$ in height visited ER with aphasia and right hemiplegia (photograph in the intervention room for the procedure). (B) Abdominal CT showed severe inguinal hernia that intestines migrated into the scrotum. (C) Initial non-enhanced CT demonstrated no evidence of hemorrhage or definite low density. (D) CT angiogram (coronal view) showed left distal ICA occlusion due to a thrombus (white arrow) and only a slight anterotemporal flow was observed, whereas ipsilateral proximal A1 and MCA distal blood flow were not detected.

\section{CASE REPORT}

A 35-year-old achondroplasia male patient visited the emergency room with right hemiplegia (motor grade II) and aphasia within 6 hours after onset. He had a clinical history of moderate mitral valve stenosis and near bedridden state due to severe inguinal hernia for the last 3 years (Fig. 1A, B). Initial vital signs were stable and routine laboratory findings were non-specific. The National Institute of Health Stroke Scale (NIHSS) was 14. Initial non-contrast computed tomography (CT) showed no definite low density, but angiography demonstrated the total occlusion of the left internal cerebral artery because of acute thrombosis (Fig. 1C, D). We decided to perform the mechanical thrombectomy immediately after careful consideration of the anatomical characteristics of only $130 \mathrm{~cm}$ tall patient. The CT angiogram in the emergency room was checked the diameters of the non-occluded MCA, ICA, and CCA, and we measured as $3.0 \mathrm{~mm}, 4.2 \mathrm{~mm}$, and $8.2 \mathrm{~mm}$, respectively (Fig. 2A-C). Experientially, it was not different from other patients, and we planned to use devices of general size.

\section{Endovascular procedure}

After groin puncture of the right femoral artery, a $65 \mathrm{~cm}$ 8-F Super arrow-flex sheath (Arrow international Inc., PA, USA) was placed in the left common carotid artery combined with $100 \mathrm{~cm}$ 5-F Davis diagnostic catheter (Jungsung medical, Korea) coaxially. An angiogram obtained subsequent to a left internal carotid artery (ICA) injection confirmed the occlusion of distal ICA with thrombus (Fig. 3A). A $95 \mathrm{~cm} \mathrm{8-F}$ 


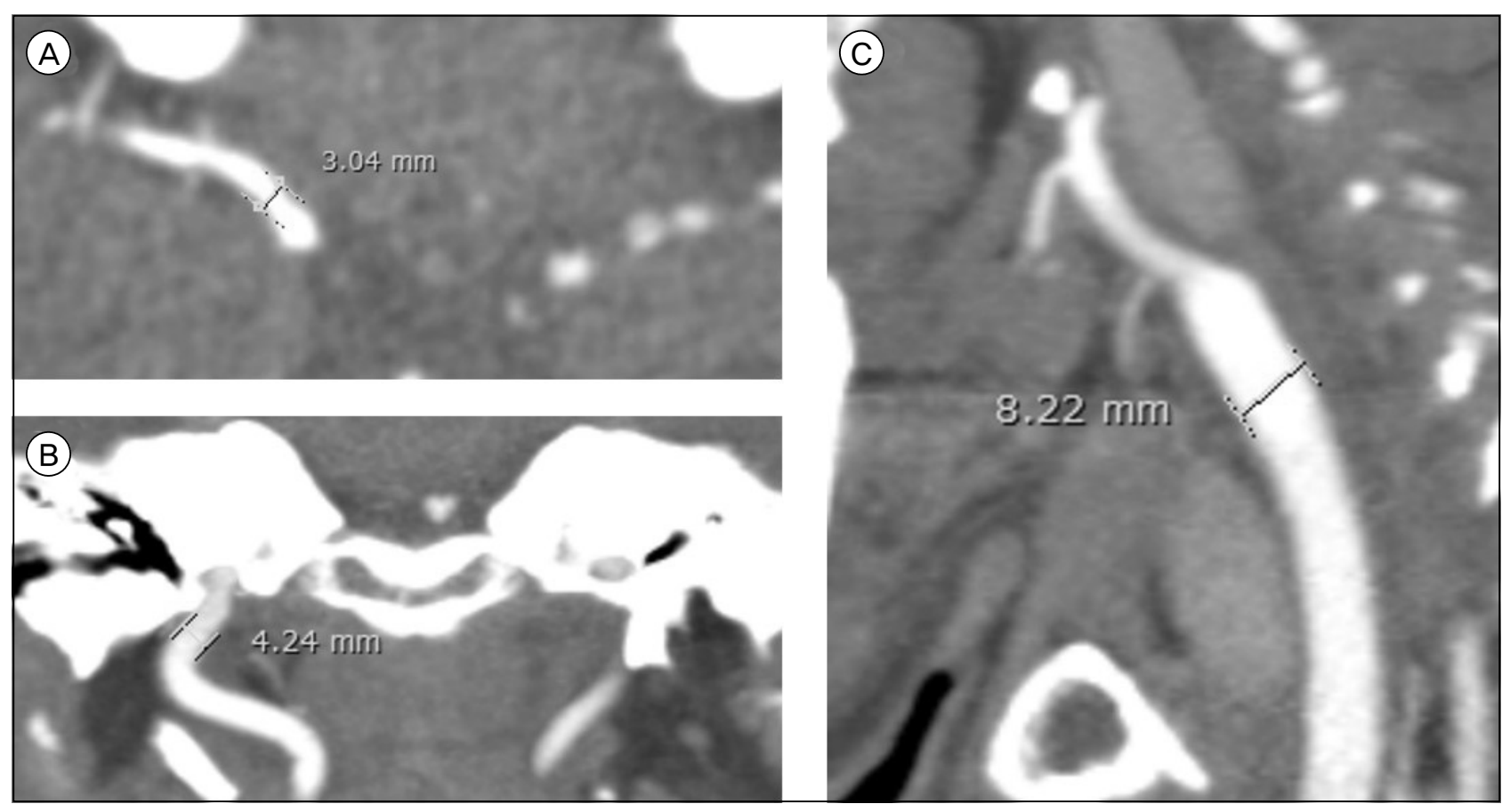

Fig. 2. To determine the use and sizes of thrombectomy devices, the initial $C T$ angiogram was checked the normal diameters of contralateral MCA (A), ICA (B), and CCA (C), and we measured as $3.0 \mathrm{~mm}, 4.2 \mathrm{~mm}$, and $8.2 \mathrm{~mm}$, respectively.

Flow gate $2^{\mathrm{TM}}$ balloon guiding catheter (BGC) (Concentric medical, CA, USA) was navigated in the cervical ICA. An AXS Catalyst ${ }^{\text {TM }} 6$ (CAT 6), distal access catheter (Stryker neurovascular, CA, USA), and a 0.027 inch Excelsior XT-27 microcatheter (Stryker neurovascular) were advanced into the proximal aspect of the thrombus in the distal ICA and past the thrombus in the middle cerebral artery (MCA), respectively, guided by the 0.014 inch Synchro-14 microwire (Stryker neurovascular). The $6 \times 25 \mathrm{~mm}$ Trevo XP provue retriever (Concentric medical) was deployed across the thrombus via the microcatheter. After waiting for about 3 minutes, the BGC was inflated to arrest the flow and the Trevo, microcatheter and CAT 6 were drawn slowly through the BGC while aspirating the BGC and CAT 6 with a $50 \mathrm{ml}$ syringes. After removing these thrombectomy devices with solumbra technique, ${ }^{35(5)}$ the BGC was deflated again and angiography was performed to confirm the recanalization of the ICA.

The first attempt was unsuccessful, but the second attempt led to complete recanalization with Thrombolysis In Cerebral Infarction (TICI) 3 in the same way (Fig. 3B, C). The procedure took 37 minutes from puncture to recanalization and some thrombi were obtained from the syringe aspirating the distal access catheter (CAT6) (Fig. 3D).

\section{Post-procedure course}

There were no complications related to the procedure and the next day, the patient showed improvement in neurological symptoms from NIHSS 14 to 5 and his right arm and leg strength from grade II to IV. On post-procedure day 3, the brain CT angiogram confirmed that left ICA was well maintained after reperfusion (Fig. 4A, B). Dual antiplatelet therapy (aspirin $100 \mathrm{mg}$ and clopidogrel $75 \mathrm{mg}$ ) was continued after the procedure. A few weeks later, he was transferred to another department due to the underlying problems, but his improved neurologic status and MR angiography were well sustained even at 3 months follow-up (Fig. 4C). 

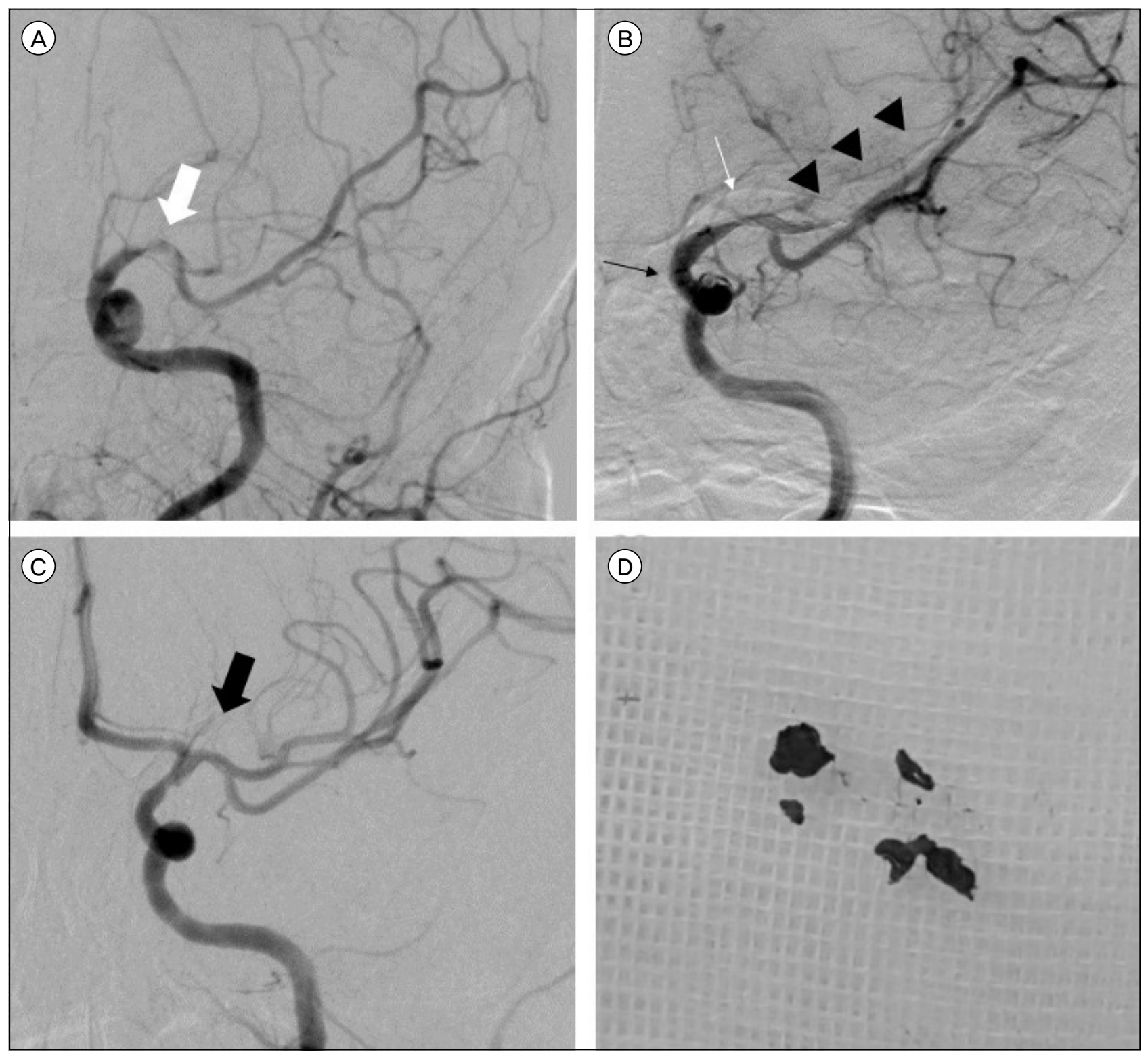

Fig. 3. (A) Diagnostic ICA angiogram showed anterotemporal artery flow but ACA and MCA flow was not detected because of thrombus (white arrow). (B) During waiting 3 min after deploying the Trevo XP $6 \times 25 \mathrm{~mm}$ (white arrow) with AXS Catalyst ${ }^{\text {TMM }} 6$ (blackarrow) at the first trial, distal MCA flow was weakly observed, (arrow heads) but no ACA flow was detected due to thrombus in the stent. (C) After second thrombectomy trial, both ACA and MCA flow was completely reperfused with TICl 3. (black arrow) (D) Some thrombi were obtained from aspirating the AXS Catalyst ${ }^{\mathrm{TM}} 6$, but no clots were found in retriever stent and balloon guiding catheter.

\section{DISCUSSION}

Achondroplasia is a relatively infrequent disorder, but various problems related to this disorder and a few experiences associated with treatment have been reported. ${ }^{49) 17118 / 24)}$ Based on the publication of several clinical trials, ${ }^{1227714) 22}$ the endovascular treatment of acute ischemic stroke (AIS) has been regarded as a standard treatment and its benefits have been reported in most of the patients regardless of various conditions. ${ }^{819)}$ However, there exist no studies or guidelines for treatment of patients with AIS and achondroplasia. Furthermore, there was only a few reports on interventional therapy of coronary artery disease in achondroplasia, ${ }^{2023)}$ however, there are no reports on neuro-interventional therapy (similar to the 

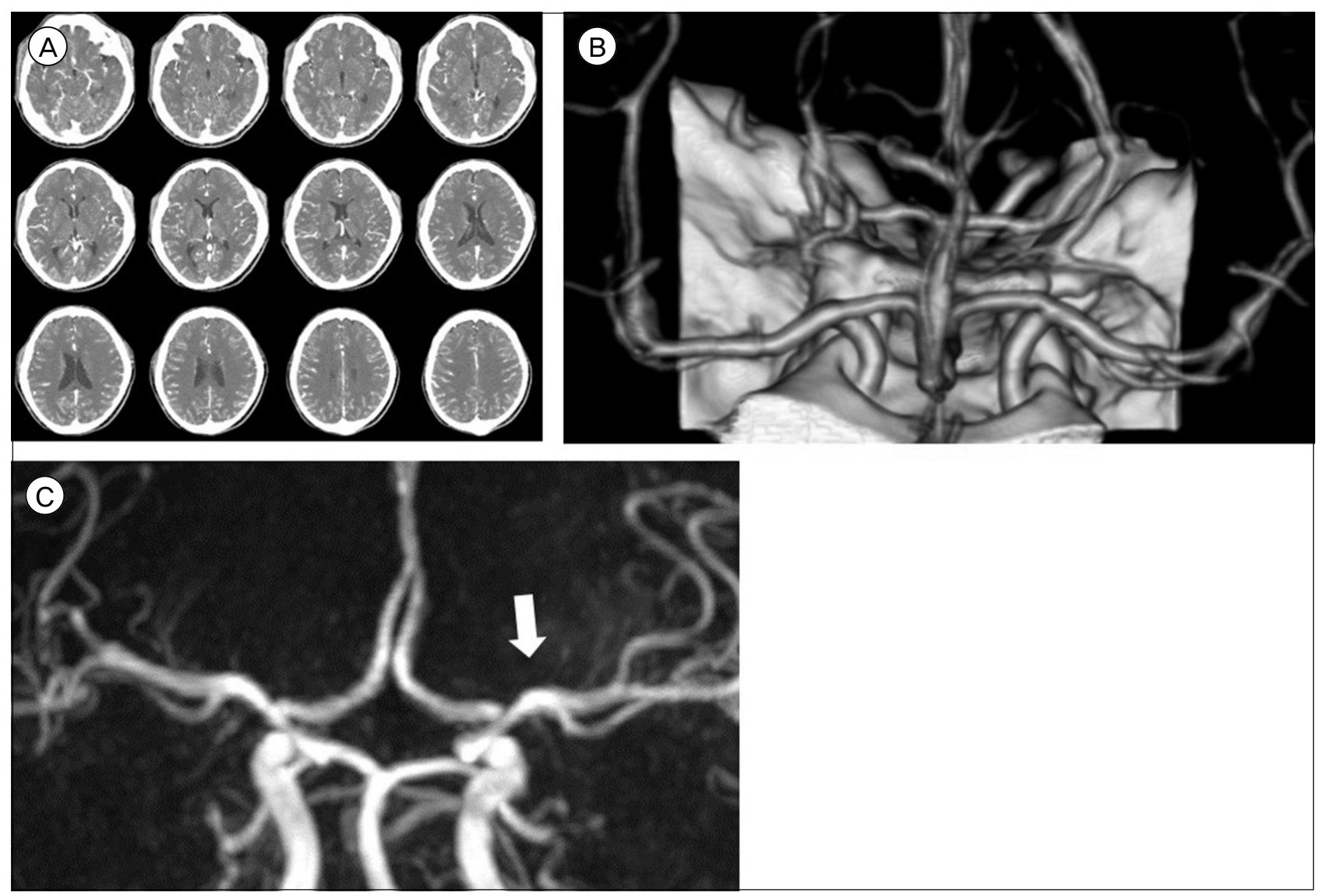

Fig. 4. After 3 days post procedure, there was no definite hemorrhage or low density in left MCA territory on enhanced brain CT (A) and the volume rendered reconstruction also showed intact left MCA (B). Three months later, follow-up MR angiography revealed well maintained completely reperfused MCA (white arrow) (C).

present case).

Several studies reported the measurement of the MCA, ICA, and CCA in the range of approximately 3 to $5 \mathrm{~mm}, 4$ to $6 \mathrm{~mm}$ and 5 to $8 \mathrm{~mm}$, respectively. ${ }^{13) 16)}$ Although the height of these patients ranged from about 125 to $137 \mathrm{~cm}$, no data were available on their vessels size. ${ }^{1012)}$ As shown in figure 2, the MCA, ICA, and CCA were measured as $3.0 \mathrm{~mm}, 4.2 \mathrm{~mm}$, and 8.2 $\mathrm{mm}$, respectively, which were not significantly different from that of the general population. So, we attempted the mechanical thrombectomy with the commonly used size of retrieval stent, distal access catheter, and BGC devices. The use of the femoral puncture and closure device did not differ from the general public, and was successfully performed without other problems.
We performed an endovascular thrombectomy using a Trevo XP as stent-retriever and CAT6 as a large bore aspiration catheter simultaneously, so-called "solumbra technique", combined with the BGC. Our intention was to effectively remove any kinds of clots and to reduce the incidence of thrombus fragmentation and distal embolization at the same time.3)(515) Furthermore, as $\mathrm{Yi}$, et al reported that Trevo XP $6 \times$ $25 \mathrm{~mm}$ stent had better clinical and angiographic outcome than $4 \times 20 \mathrm{~mm}^{28)}$ we were able to achieve desired results using oversized-stents larger than the patient's vessel size.

\section{CONCLUSION}

The treatment of AIS was not established in achon- 
droplasia with various complications. Although further anatomical and clinical studies are required concerning these patients, it could also be an effective method for the treatment that the mechanical thrombectomy using "solumbra technique" and thrombectomical devices for the general populations.

\section{Disclosure}

The authors report no conflict of interest concerning the materials or methods used in this study or the findings specified in this paper.

\section{Ethics approval}

This case report followed Declaration of Helsinki guidelines for studies with human individuals.

\section{REFERENCES}

1. Berkhemer OA, Fransen PS, Beumer D, van den Berg LA, Lingsma HF, Yoo AJ, et al. A randomized trial of intraarterial treatment for acute ischemic stroke. N Engl J Med. 2015 Jan 1;372(1):11-20.

2. Campbell BC, Mitchell PJ, Kleinig TJ, Dewey HM, Churilov L, Yassi N, et al. Endovascular therapy for ischemic stroke with perfusion-imaging selection. N Engl J Med. 2015 Mar 12;372(11):1009-18.

3. Chueh JY, Puri AS, Wakhloo AK, Gounis MJ. Risk of distal embolization with stent retriever thrombectomy and ADAPT. J Neurointerv Surg. 2016 Feb;8(2):197-202.

4. Daugherty A. Achondroplasia: Etiology, Clinical Presentation, and Management. Neonatal Netw. 2017 Nov 1;36(6): 337-42.

5. Deshaies EM. Tri-axial system using the Solitaire-FR and Penumbra Aspiration Microcatheter for acute mechanical thrombectomy. J Clin Neurosci. 2013 Sep;20(9):1303-5.

6. Dubiel L, Scott GA, Agaram R, McGrady E, Duncan A, Litchfield KN. Achondroplasia: anaesthetic challenges for caesarean section. Int J Obstet Anesth. 2014 Aug;23(3): 274-8.

7. Goyal M, Demchuk AM, Menon BK, Eesa M, Rempel JL, Thornton J, et al. Randomized assessment of rapid endovascular treatment of ischemic stroke. $\mathrm{N}$ Engl J Med. 2015 Mar 12;372(11):1019-30.

8. Goyal M, Menon BK, van Zwam WH, Dippel DW, Mitchell PJ, Demchuk AM, et al. Endovascular thrombectomy after large-vessel ischaemic stroke: a meta-analysis of individual patient data from five randomised trials. Lancet. 2016 Apr 23;387(10029):1723-31.

9. Hecht JT, Francomano CA, Horton WA, Annegers JF. Mortality in achondroplasia. Am J Hum Genet. 1987 Sep;41(3):454-64.

10. Hoover-Fong J, McGready J, Schulze K, Alade AY, Scott CI. A height-for-age growth reference for children with achondroplasia: Expanded applications and comparison with original reference data. Am J Med Genet A. 2017 May;173(5):1226-30.

11. Horton WA, Hall JG, Hecht JT. Achondroplasia. Lancet. 2007 Jul 14;370(9582):162-72.

12. Horton WA, Rotter JI, Rimoin DL, Scott CI, Hall JG. Standard growth curves for achondroplasia. J Pediatr. 1978 Sep;93(3):435-8.

13. Jain KK. SOME OBSERVATIONS ON THE ANATOMY OF THE MIDDLE CEREBRAL ARTERY. Can J Surg. 1964 Apr;7:134-9.

14. Jovin TG, Chamorro A, Cobo E, de Miquel MA, Molina CA, Rovira A, et al. Thrombectomy within 8 hours after symptom onset in ischemic stroke. N Engl J Med. 2015 Jun 11;372(24):2296-306.

15. Kang DH, Park J. Endovascular Stroke Therapy Focused on Stent Retriever Thrombectomy and Direct Clot Aspiration: Historical Review and Modern Application. J Korean Neurosurg Soc. 2017 May;60(3):335-47.

16. Krejza J, Arkuszewski M, Kasner SE, Weigele J, Ustymowicz A, Hurst RW, et al. Carotid artery diameter in men and women and the relation to body and neck size. Stroke. 2006 Apr;37(4):1103-5.

17. Melekoglu R, Celik E, Eraslan S. Successful obstetric and anaesthetic management of a pregnant woman with achondroplasia. BMJ Case Rep. 2017 Oct 25;2017.

18. Miyazaki M, Kanezaki S, Notani N, Ishihara T, Tsumura H. Spondylectomy and lateral lumbar interbody fusion for thoracolumbar kyphosis in an adult with achondroplasia: A case report. Medicine (Baltimore). 2017 Dec;96(49):e8983.

19. Powers WJ, Derdeyn CP, Biller J, Coffey CS, Hoh BL, Jauch EC, et al. 2015 American Heart Association/ American Stroke Association Focused Update of the 2013 Guidelines for the Early Management of Patients With Acute Ischemic Stroke Regarding Endovascular Treatment: A Guideline for Healthcare Professionals From the American Heart Association/American Stroke Association. Stroke. 2015 Oct;46(10):3020-35.

20. Rahman N, Nabi A, Gul I. Sheathless transradial coronary angioplasty in an achondroplasic patient with ST elevation myocardial infarction. BMJ Case Rep. 2015 Oct 27;2015.

21. Rousseau F, Bonaventure J, Legeai-Mallet L, Pelet A, Rozet JM, Maroteaux P, et al. Mutations in the gene encoding fibroblast growth factor receptor-3 in achondroplasia. Nature. 1994 Sep 15;371(6494):252-4.

22. Saver JL, Goyal M, Bonafe A, Diener HC, Levy EI, Pereira VM, et al. Stent-retriever thrombectomy after intravenous t-PA vs. t-PA alone in stroke. N Engl J Med. 2015 Jun 11;372(24):2285-95.

23. Srinivas SK, Ramalingam R, Manjunath CN. A rare case of percutaneous coronary intervention in achondroplasia. J Invasive Cardiol. 2013 Jun;25(6):E136-8.

24. Susarla SM, Mundinger GS, Kapadia H, Fisher M, Smartt J, Derderian C, et al. Subcranial and orthognathic surgery for obstructive sleep apnea in achondroplasia. J Craniomaxillofac Surg. 2017 Dec;45(12):2028-34.

25. Unger S, Bonafe L, Gouze E. Current Care and 
Investigational Therapies in Achondroplasia. Curr Osteoporos Rep. 2017 Apr;15(2):53-60.

26. Waller DK, Correa A, Vo TM, Wang Y, Hobbs C, Langlois $\mathrm{PH}$, et al. The population-based prevalence of achondroplasia and thanatophoric dysplasia in selected regions of the US. Am J Med Genet A. 2008 Sep 15;146a(18):2385-9.

27. Wynn J, King TM, Gambello MJ, Waller DK, Hecht JT.
Mortality in achondroplasia study: a 42-year follow-up. Am J Med Genet A. 2007 Nov 1;143a(21):2502-11.

28. Yi HJ, Sung JH, Lee DH, Hong JT, Lee SW. Single-Center Experience of Mechanical Thrombectomy with the Trevo XP ProVue $6 \times 25 \mathrm{~mm}$ Stent Retriever in Middle Cerebral Artery Occlusion: Comparison with Trevo XP ProVue $4 \times 20 \mathrm{~mm}$. World Neurosurg. 2017 Nov;107:649-56. 